\section{A NOTE ON TWO UNUSUAL COMPLICATIONS OF MIDWIFERY.}

By J. B. Pike, M.R. C.S. Eng.

ON Oct. 2nd, 1896, I attended a multiparous woman. On arriving I found a tumour protruding from the anterior part of the vagina. It was somewhat difficult to ascertain its nature. In consistence it was something like dough, covered by mucous membrane, but with an indistinct feeling of fluctuation. It was almost plum-coloured, and about 2 in. long by 1 in. broad. Emptying the bladder had no effect upon it, and on making a complete examination it was found to be continuous with the os uteri. The head of the fotus was lodged on the pubes of a somewhat narrow pelvis. I delivered with forceps under chloroform, and the elongated and oedematous anterior lip of the os, for it was this which formed the swelling, gradually receded without any serious symptoms.

On Jan. 15th, 1897, I attended a married woman. A midwife was in charge of the case, and her history of it was that it was something "she had never seen before." There was a contraction of the vaginal outlet so great that one finger could only be inserted with some force, and then only up to the middle joint. The woman had already borne a child with a natural labour. The contracted band, which was probably cicatricial, was divided by multiple incisions under chloroform, until sufficient room was gained to dilate with the hand, and the case was completed with forceps. Posteriorly a finger could be passed under the mucous membrane, between the vagina and the rectum, but owing in great measure to the excellent nursing of our district nurse the case went on very favourably.

Loughborough.

\section{NOTE ON A CASE OF ACUTE ASCENDING PARALYSIS.}

By E. Cecil Wrlliams, M.B. Cantab.,

PHYSICTAY IN CHARGE OF OUT-PATIENTS, HOSPITAX FOR SICK CHILDREY AND WOMEN, BRISTOL.

THE probable diagnosis of the following case rests almost entirely on the history given by the mother, as the child was seen only twice just before death. The mother refused to allow the child to be admitted into the hospital, and it was impossible to obtain permission for a post-mortem examination. There had been seven children, the fifth and sixth of whom had died at ten weeks. The mother said that both had appeared perfectly healthy at birth. At the end of the first week she noticed that they did not kick when they had their baths, they gradually got weaker, the paralyses extending upwards, and both died at ten weeks, with inability to swallow or cry and failure of respiration-symptoms of bulbar paralysis. The elder children were perfectly healthy. The youngest, a full time male child, appeared at birth to be quite healthy. At the end of the first week the mother noticed that the child did not use his legs. She said that he gradually got more feeble, but not so rapidly as the two previous children had done. At six weeks the mother noticed the breathing to be peculiar. When I first saw the child two weeks before his death he was in the following condition. The arms were slightly flexed, the forearm and hand were in a position of hyperpronation. It was impossible to fully extend the forearm on the arm; the tendon of the biceps could be felt perfectly tense when an attempt was made to extend the forearm. It was also impossible to fully supinate the hand and forearm; the fingers were slightly flexed into the palm. The intercostals were paralysed; there was diaphragmatic breathing. The abdominal muscles did not move. The legs and feet lay motionless and perfectly helpless; there were no contractures of the feet. The kneejerks were abolished, and the plantar reflexes were almost absent. There was no muscular wasting, and sensibility did not seem to be impaired. The child did not have any diffculty in passing urine or motions; the latter were very offensive. He rapidly became worse, was unable to swallow, there was difficulty of respiration and inability to cry, and he died aged four months and two weeks. From the mother's account, which I have every reason to believe is a correct one, there seems to be no doubt that it was an ascending paralysis.
There had not been any difficulty at birth; the labour was natural. There was no history of syphilis; the mother was perfectly healthy. She never noliced any sore on the cord that. could have been the means of entry of any poison. There did: not appear to be any swelling of the spleen or any of the mesenteric glands. They lived in a perfectly healthy house. in the country; there was no history of malaria.

Landry's parslysis has occurred very rarely in children. ${ }^{\mathrm{i}}$ A case has been recorded in a boy aged eleven years, but it. may possibly have been a case of peripheral neuritis; theboy recovered. ${ }^{2}$ A case of ascending paralysis after whooping-cough has been recorded in a boy aged three years. The case recovered. It was regarded as of toxic origin." Landry's paralysis is now regarded as being caused by a. toxin. The occurrence of the disease in three successive. children, commencing in the same way and running an. almost identical course would in this case seem to suggest a. common cause, possibly of toxic origin. The progress of this case was perhaps somewhat slow, but the symptoms fit in extremely well with those of Landry's paralysis, as given by Diller and Meyer. ${ }^{4}$

Clifton, Bristol.

\section{NOTES OF TWO CASES OF DERMATITIS FROM CONTACT WITH THE PLANT" ANGELICA."}

By David Walsh, M.D. Edin., PHYSICLAN TO THE WESTERN SKIN HOSPITAL, LONDON.

THE dermatitis venenata set up by contact of the skin with various drugs and plants is interesting from various points of view. In this country perhaps the most common form in recent years is that due to the "primula obconica." A short while since two cases of acute dermatitis caused by gathering the plant "angelica" came under my notice.

A youth, aged eighteen years, a confectioner, pale, but apparently well-nourished, presented himself at the Western Skin Hospital on May 24th, complaining of an irritating. rash on the forearms. He himself attributed the attack to the gathering of the plant "angelica," which he called "cow's parsley," in Regent's Park six days previously. When cutting the plant he had his sleeves rolled up and the leaves and juices came freely into contact with the front of the forearms. Next day he was attacked with an intensely burning and itching pain. On examination the parts indicated were found to be in an acutely inflamed condition and the inflammation was rapidly spreading both round to the back of the forearms and down to the hands. On the right forearm was a broken bleb the size of a shilling. The patient stated that a friend who helped him in gathering the plant. was attacked in a similar fashion. In the friend's case, however, there was much more blistering and less pain, and the patient recorered in a few days under treatment with a simple zinc ointment. This rapid cure is interesting when compared with the intensity of the process in the patient who came to the hospital, and in whom the dermatitis persisted for several we eks.

I have been unable to find any record of similar cases, although the plant, or rather its resin, is mentioned by Fernie as a skin stimulant. In the present case it was gathered for the purposes of preserving. When candied it is used very largely by confecticners for ornamenting cakes, and is not unlike fine green stalks of celery in appearance. In his book on "Herbal Simples" Fernie gives the following account of "angelica" (or " master-wort"): "The wild Angelica grows commonly throughout England as an umbelliferous plant, with a tall, hollow stem, out of which boys like to make pipes. It is purple, furrowed, and downy, bearing white flowers tinged with pink. But the herb is not useful as a simple until cultivated in our gardens, the larger variety being chosen for this parpose, and bearing the name Archangelica. It came to this country from northern latitudes in 1568. The aromatic stems are grown abundantly near London in moist fields for the use of confectioners. These stems when candied are sold as a favourite sweetmeat; they are grateful to the feeble stomach and will relieve flatulence promptly. The roots of the garden Angelica

I Starr's American Text-book of Diseases of Children.

2 Ashby and Wright: Diseases of Children, Medical and Surgical. . 3 Brit. Med. Jour., Aug. 13th, 1887.

4 American Journal of the Medical Sciences, April, 1896.

5 The patient was shown at the meeting of the Dermatologica, Society of Great Britain and Ireland on May 26 th. 